06

\title{
Исследование структурных и оптических свойств углеродных нановолокон
}

\author{
(C) А.А. Бабаев, ${ }^{1}$ М.Е. Зобов, ${ }^{1}$ Е.И. Теруков, ${ }^{2,3}$ С.В. Ткачев ${ }^{4}$ \\ ${ }^{1}$ Институт фризики им. Х.И. Амирханова Дагестанского научного центра РАН, \\ 367003 Махачкала, Россия \\ ${ }^{2}$ Физико-технический институт им. А.Ф. Иоффре РАН, \\ 194021 Санкт-Петербург, Россия \\ ${ }^{3}$ Санкт-Петербургский государственный электротехнический университет „ЛЭТИ“ им. В.И. Ульянова (Ленина), \\ 197022 Санкт-Петербург, Россия \\ ${ }^{4}$ Тамбовский государственный технический университет, \\ 392000 Тамбов, Россия \\ e-mail: babaev-arif@mail.ru
}

Поступило в Редакцию 14 марта 2019 г.

В окончательной редакции 12 сентября 2019 г.

Принято к публикации 18 сентября 2019 г.

Представлены экспериментальные данные по агрегатным массивным клубкам (объемом до $1 \mathrm{~cm}^{-3}$ ) из углеродных нановолокон (УНВ) диаметром 35-40 nm и длиной $1000 \mathrm{~nm}$. Приведены результаты исследования агрегации УНВ в микроскопическом и в макроскопическом масштабах, микрорамановской спектроскопии при различных энергиях возбуждения. Исследовано поглощение в видимой и ультрафиолетовой областях, которое позволило оценить работу выхода электронов из УНВ.

Ключевые слова: углеродные нановолокна, нанотрубки, комбинационное рассеяние света, агрегация.

DOI: 10.21883/JTF.2020.03.48927.92-19

\section{Введение}

Углеродные нановолокна (УНВ) представляют собой цилиндрические наноструктуры сложенных стопкой слоев графена в виде конусов „чашек“ или пластин. Углерод может существовать в форме трубчатых микроструктур называемых волокнами или нитями. Углеродные нанотрубки (УНТ) и УНВ вызывают большой интерес благодаря своим необычным механическим, электрофизическим и магнитным свойствам. Количество фундаментальных и прикладных исследований углеродных наноструктур (УНС) постоянно растет. Разработка эффективных технологий получения УНС открывает широкие перспективы их применения в водородной энергетике для создания водород-аккумулирующих материалов и электродов топливных элементов, в катализе - в качестве носителей катализаторов, в наноэлектронике для создания одномерных проводников, наноразмерных транзисторов, холодных эмиттеров электронов и суперконденсаторов. Одним из наиболее перспективных методов синтеза УНС является каталитический пиролиз различных углеродсодержащих соединений. Метод позволяет получать УНС в больших количествах и дает возможность вести направленный синтез УНС на катализаторах, регулярно нанесенных на различные подложки.

Одной из основных проблем при каталитическом синтезе УНС является получение с высокой селективностью углеродного материала желаемой структуры и c необходимыми физико-химическими характеристиками. Анализ литературных данных показывает, что на строение и свойства УНС существенное влияние оказывают химическая природа и размер частиц активного компонента катализатора, способы его закрепления на различных носителях (подложках), химическая природа и пористость носителя, давление, температура пиролиза, состав исходной газовой смеси, а также продолжительность процесса. Использование в качестве катализаторов бинарных смесей металлов, металлических композитов или интерметаллических соединений, а также введение в состав катализатора различных добавок в ряде случаев изменяет эффективность процессов образования и роста УНС.

Настоящая работа посвящена получению и характеризации УНВ с помощью оптических методов и исследованию методом электронной микроскопии. На основе УНВ и лаков были изготовлены композиты, которые обладают радиопоглощающими свойствами [1].

\section{Экспериментальная часть}

Немодифицированные УНМ получают в ООО „ТИТЦМ“ Тамбовского государственного технического университета, путем каталитического пиролиза метана на специальным образом подготовленной подложке с нанесенным на нее катализатором (никель) в виде мелкодисперсного порошка. Немодифицированные УНМ производителя ООО „ТИТЦМ“ в сравнении с УНТ 


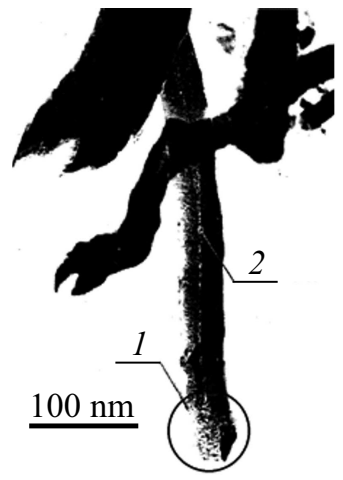

TEM

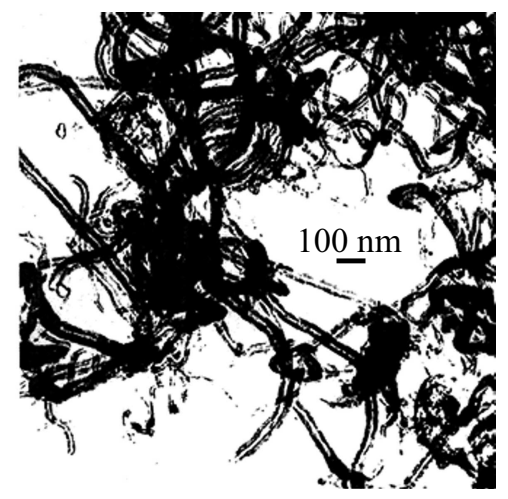

SEM
Рис. 1. Данные электронной микроскопии немодифицированных УНВ: 1 - скрытая часть катализатора; 2 - центральная борозда, характерная для шевронного типа.
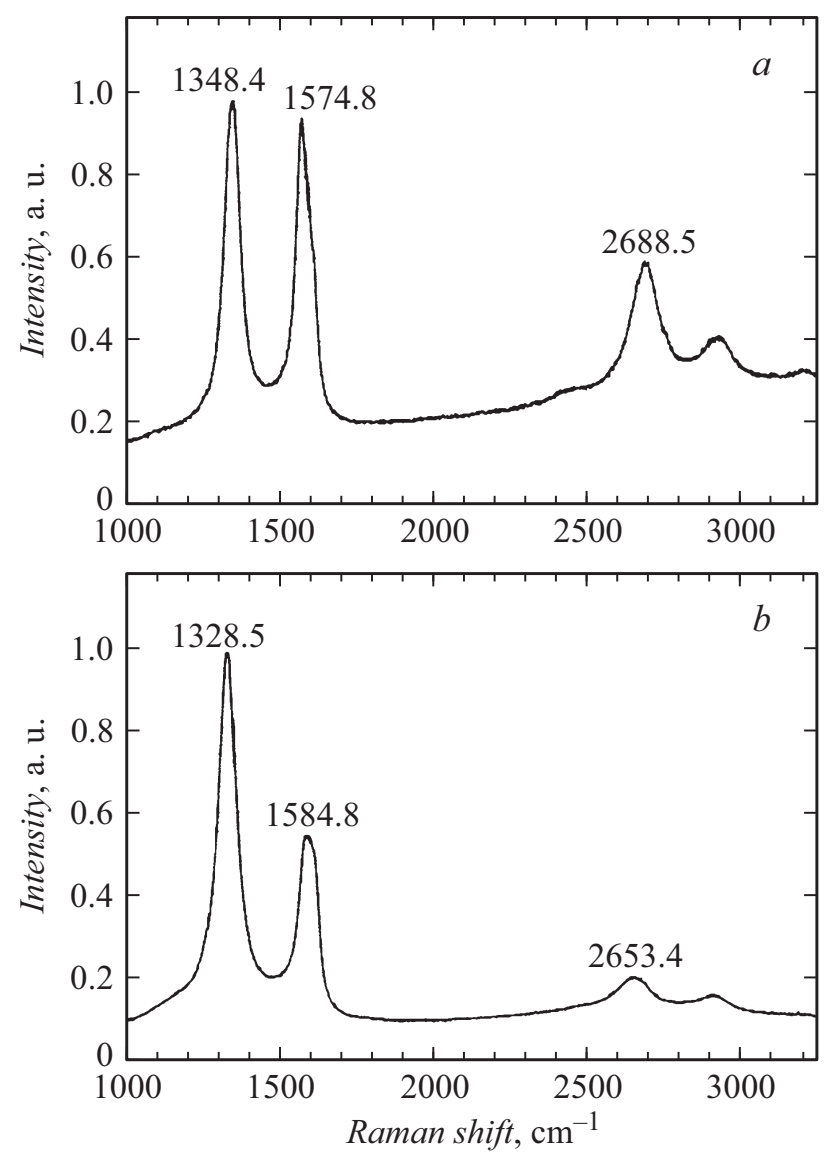

Рис. 2. Микрорамановская спектроскопия УНВ, дисперсия спектров при возбуждении: $a-\lambda=0.514 \mu \mathrm{m}, b-$ $\lambda=0.63 \mu \mathrm{m}$.

производителя IljinNanotech (Южная Корея) больше напоминает УНВ, а не нанотрубки. Поэтому в дальнейшем для его отличия будет использоваться аббревиатура УНВ. Исследовался как продукт, непосредственно получаемый из реактора, так и очищенный в первую очередь от примеси никеля, для чего проводилась обработка азотной кислотой. Зольность такого УНВ составляет около $1 \%$ преимущественно за счет остаточного содержания никеля [2]. Полученные СЭМ и ПЭМ изображения наноструктуры УНВ приведены на рис. 1.

Анализируя приведенные на рис. 1 изображения, можно сделать следующие выводы:

- размер УНВ составляет от 35 до $40 \mathrm{~nm}$ в поперечнике и до $1 \mu \mathrm{m}$ в длину. Сечение волокна определяется кристаллографией металлической подложки в соответствии с базовыми представлениями о процессе роста нановолокна;

- в исследуемом материале присутствует как параллельная структура, так и шевронный ее тип. Для волокон параллельной структуры диаметр канала составляет $10-20 \mathrm{~nm}$. Угол наклона графитовых плоскостей для шевронного типа близок к $45^{\circ}$;

- в концевых участках углеродного волокна шевронного типа идентифицируются металлические частицы, происхождение которых объясняется захватом частиц катализатора при синтезе [3]. Оценка магнитной восприимчивости порошка УНВ показывает значение, соответствующее ферромагнитным включениям, т. е. имеет место действительно присутствие частиц Ni-катализатора.

Смесь двух типов УНВ (параллельного и шевронного) представляет существенные затруднения как с точки зрения определения их относительного содержания, так и физического разделения нановолокон по типу структуры. Для макроскопических количеств УНВ на сегодняшний день не разработано методов, позволяющих эффективно решать эту задачу. Одна из принципиальных сложностей в этом случае - сильно выраженная агрегация УНВ как в микроскопическом масштабе (что хорошо видно на ТЕМ-микрофотографии), так и в макроскопическом. Нановолокна быстро агрегируют в глобулы, увеличивающиеся по мере хранения - как в виде порошка, так и в жидкой среде. Глобулы имеют высокую эластичность и существенную пористость: при насыпной плотности $0.4 \mathrm{~g} / \mathrm{cm}^{3}$ пикнометрическая плотность составляет $1.6 \mathrm{~g} / \mathrm{cm}^{3}$.

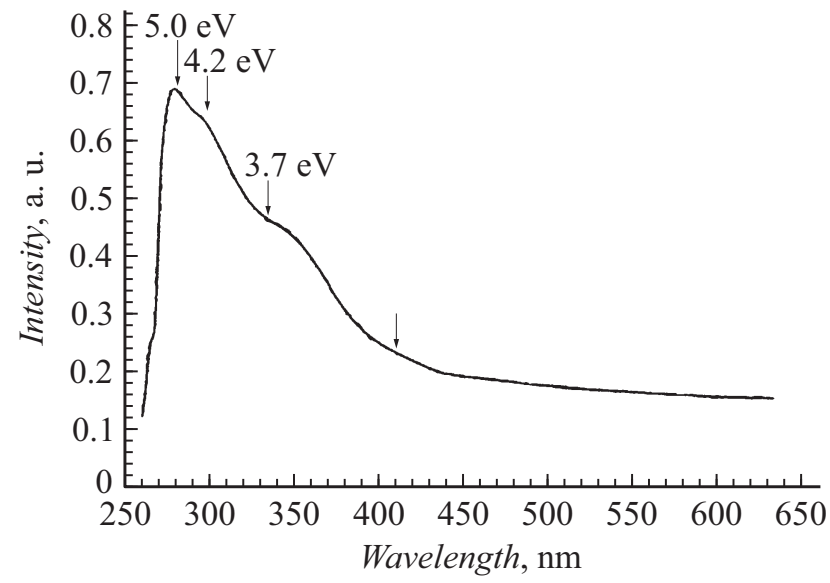

Рис. 3. Спектр поглощения УНВ. 

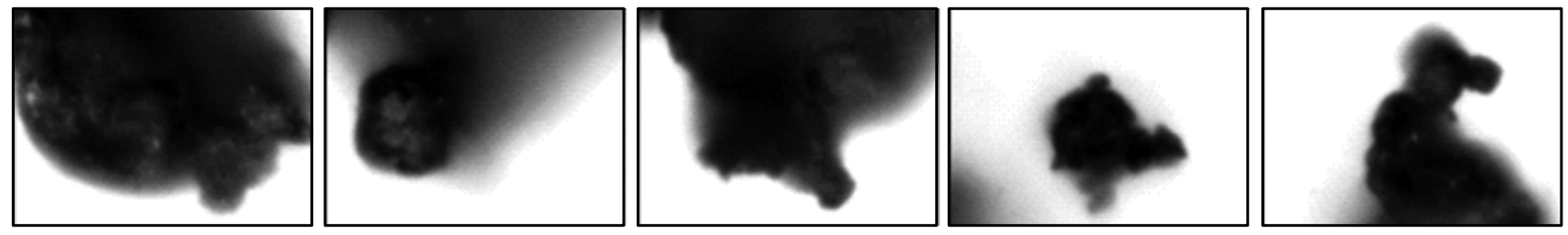

Рис. 4. Микрофотографии частиц УНВ: размер кадра $100 \times 75 \mu \mathrm{m}$.
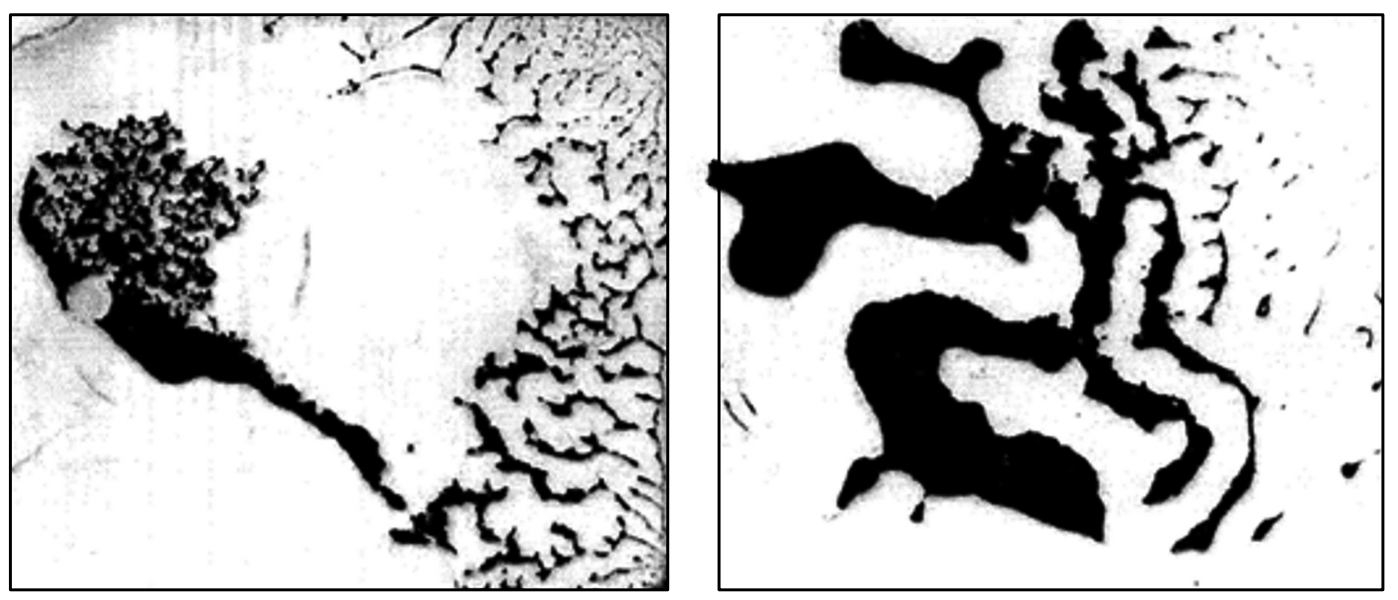

Рис. 5. Макроскопическая самоорганизация УНВ: размер кадра $29 \times 25 \mathrm{~mm}$. Слева - фронтальная размерность контура фрагмента (значение $D=1.3$ ).

Ниже приведены параметры использованных нами для сравнения импортных УНТ; часть этих сведений принята по спецификациям производителя „IljinNanotech“ (Южная Корея):

- УНТ являются многостенными со внешним диаметром $10-25 \mathrm{~nm}$ и длиною $10-50 \mathrm{~nm}$;

- пористость 0.47 и $0.83 \mathrm{~cm}^{3} / \mathrm{g}$ соответственно по измерениям адсорбции и десорбции азота;

- макроскопически усредненная проводимость составляет от 0.3 до $2 \mathrm{~ms} / \mathrm{cm}$ в зависимости от интенсивности прессовки порошка УНТ;

- наблюдается микроскопическая агрегация нанотрубок, однако существенно менее выраженная, чем в случае УНВ.

Для характеризации УНВ существенную роль играет метод микрорамановской спектроскопии. Измеренные спектры получены для разных длин волн возбуждающего излучения, соответствующих красной и зеленой линиям использованного лазера. Возможность изучения дисперсии рамановских спектральных линий позволяет более обоснованно делать выводы о свойствах изученных УНВ. На рис. 2 приведена одна из характерных пар спектров.

Пики в области $1320-1340 \mathrm{~cm}^{-1}$, как правило, соотносят с алмазной $s p^{3}$-фазой (точное значение для алмаза $\left.1332 \mathrm{~cm}^{-1}\right)$, однако надо принимать во внимание, что пиролитический графит имеет близкий пик $1355 \mathrm{~cm}^{-1}$ [4]. По параметрам дисперсии можно установить, что наблюдаемая линия соответствует именно нанографиту, а не алмазной фазе. Это подтверждается и наличием сильной полосы $1574-1584 \mathrm{~cm}^{-1}$, поскольку как монокристаллический, так и пиролитический графит обладают пиком $1580 \mathrm{~cm}^{-1}[5]$.

Оптическая спектроскопия в видимой и ближней УФ областях позволяет оценить работу выхода электрона из УНВ. Полученные спектры характеризуются интенсивным пиком, соответствующим энергии порядка $5.0 \mathrm{eV}$, a также несколькими менее интенсивными пиками меньшей энергии. Эти пики, вероятно, обусловлены дефектами структуры, природа которых пока не ясна. На рис. 3 приведен один из полученных спектров (экспериментальная зависимость аппроксимирована четырьмя гауссианами).

Как видим, для энергий выше $5.0 \mathrm{eV}$ наблюдается заметный спад интенсивности поглощения. Такие величины работы выхода у углеродных структур характерны и для графита, и для алмаза. Но, принимая во внимание ширину запрещенной зоны алмаза (которая редко оказывается ниже $6 \mathrm{eV}$ ), высокая интенсивность поглощения вместе с высокой электропроводностью вполне уверенно идентифицируют графитовую фазу. Высокая интенсивность пиков оптического поглощения, а также соответствующие данные микрорамановской спектроскопии указывают на содержание в УВН аморфного углерода.

Учитывая, что УНТ дают на микрорамановских спектрах линии, которые не наблюдаются в нашем случае, по совокупности полученных данных можно с уверенностью утверждать, что исследуемый наноматериал 
состоит по преимуществу из УНВ и практически не содержит включений одностенных УНТ и фуллеренов.

Отдельный интерес представляет вопрос об агрегации УНВ как в микроскопическом, так и в макроскопическом масштабах. Представленные выше на рис. 1 изображения, полученные с помощью электронного микроскопа, дают картину взаимной организации УНВ в наномасштабе. В микромасштабе УНВ формируют плотные глобулы, состоящие из многократно переплетенных нановолокон, в целом образующих частицы размером в десятки микрон. Некоторые из типичных микрофотографий приведены на рис. 4.

Можно отметить неправильную форму наблюдаемых частиц, отсутствие выраженного рельефа (слабый рельеф, возможно, теряется из-за очень низкого отражения света от большей части поверхности частицы), наличие довольно ярких бликов с характерным графитовым блеском. Многие частицы имеют заметные „перетяжки“, которые обычно образуются при слипании нескольких частиц более правильной формы, приблизительно сферической или эллиптической. На второй из приведенных на рис. 4 микрофотографий хорошо видна сравнительно небольшая частица, попавшая в фокус, на фоне нижележащей более массивной частицы. Характерно, что не наблюдается переходной области между этим „островком“ и нижележащим массивным образованием, что должно свидетельствовать именно о слипании крупной и мелкой частиц, но не об изначальном существовании цельной частицы такой формы.

На макроскопическом уровне наблюдение агрегации УНВ дает картину еще более интересную. Был поставлен следующий опыт: в пространство между двумя плоскопараллельными стеклянными пластинами с зазором примерно $70 \mu \mathrm{m}$ была введена водная дисперсия УНВ, при этом торцы были закрыты для предотвращения испарения воды. В воду были добавлены те же сурфактанты и в той же концентрации, что использовались при приготовлении композита на основе бутадиен-стирольного латекса. Через пять суток наблюдалось насыщение адсорбатами воды поверхности нановолокон, которые по мере поглощения воды выстраивались в разветвленные структуры (рис. 5), которые, как известно, в зависимости от условий самосборки могут быть как нефрактальными, так и обладать свойствами поверхностных или массовых фракталов [6]. Проведенная оценка фрактальной размерности контура фрагмента, расположенного в левой части рис. 5, дает значение $D=1.3$. В данном опыте установлено, что в закрытом объеме на поверхности УНВ происходит интенсивная адсорбция воды (с сурфактантами) и одновременная организация УНВ в сложную разветвленную структуру. Для полимерных композитов довольно высокое содержание воды непосредственно на разветвленной поверхности углеродного остова должно иметь существенное значение.

\section{Заключение}

В УНМ производителя ООО „ИТЦМ“ установлена сильная агрегация УНВ как в микроскопическом, так и в макроскопическом масштабах. На основании исследований УНВ методом микрорамоновской спектроскопии при различных энергиях возбуждения можно с уверенностью утверждать, что исследуемый наноматериал практически не содержит посторонних включение типа одностенных УНТ либо фуллеренов. Из полученных спектров в видимой и в ближней ультрафиолетовых областях сложные пики соответствуют энергии, которая может быть аппроксимомирована четырьмя гауссианами, самый сильный из которых соответствует энергии $5 \mathrm{eV}$. Выявлена адсорбция воды нановолокнами, которые по мере поглощения воды, выстраиваются в фигуру, имеющую выраженный фрактальный характер.

\section{Конфликт интересов}

Авторы заявляют, что у них нет конфликта интересов.

\section{Список литературы}

[1] Теруков Е.И., Бабаев А.А., Ткачев А.Г., Жилина Д.В. // ЖТФ. 2018. Т. 88. Вып. 7. С. 1075-1079.

[2] Алексеев А.Г., Штагер Е.А., Козырев С.В. Физические основы технологии Stealth. СПб.: ВВМ, 2007. С. 138

[3] Золотухин И.В., Голев И.М., Маркова А.Е., Панин Ю.В., Соколов В., Ткачев А.Г., Негров В.Л. // Письма в ЖТФ. 2006. Т. 32. Вып. 5. С. 28-32.

[4] Ros T.G. Rhodium Complexes and Particles on Carbon Nanofibres: Surface Chemistry of Carbon nanofibres and Catalytic Properties of Supported Rhodium Species. Proefschriftterverkr-ging van de graad van doctor aan de Universiteit Utrecht, Utrecht, 2002.

[5] Андреев В.Д., Начальная Т.А., Созин Ю.И., Семенович В.А., Гончаров А.Ф., Габрусенок Е.В. Диагностика микроструктуры и фазового состава алмазных и алмазоподобных пленок. Труды I Междунар. семинара по алмазным пленкам. Техника средств связи. М. 1991. С. 18-29.

[6] Золь-гель технология микро- и нанокомпозитов. / Под ред. О.А. Шиловой. СПб.: Изд-во Лань, 2013. 304 с. 